\title{
Physical activity habits and preferences in the month prior to a first-ever stroke
}

Background: Physical inactivity is a powerful risk factor for stroke and other chronic diseases. The aim of this study was to explore physical activity habits and preferences in the month leading up to a first-ever stroke, and to determine whether participants were aware of the link between stroke and physical activity. Methods: We undertook an observational study with 81 participants recently admitted to a stroke unit. Participants reported their pre-morbid physical activity preferences and habits and completed the Barriers to Physical Activity and Disability Survey. Data were analysed with summative content analysis and descriptive statistics.

Results: Only $31 \%$ of participants were aware that physical inactivity was associated with stroke. Most participants defined physical activity with examples of instrumental activities of daily living (IADL) and walking (48\% of responses), and IADLs constituted their most frequent regular physical activity (38\% of responses). The barriers to physical activity reported by participants most frequently were lack of motivation (52\%), lack of interest (50\%) and lack of energy (42\%). Conclusions: Regular physical activity is important to prevent stroke and other chronic diseases but adults at risk of stroke have little awareness of the risks of physical inactivity and little motivation to undertake regular exercise. 
1 Michelle N McDonnell ${ }^{1}$, Adrian J Esterman ${ }^{2}$, Rosena Williams ${ }^{1}$, Jenny Walker ${ }^{3}$, Shylie F

2 Mackintosh $^{1}$.

$3{ }^{1}$ International Centre for Allied Health Evidence, School of Health Sciences, University of South

4 Australia, Adelaide, Australia

$5 \quad{ }^{2}$ School of Nursing and Midwifery, University of South Australia, Adelaide, Australia

$6 \quad{ }^{3}$ Physiotherapy Department, Flinders Medical Centre, Adelaide, Australia

\section{Corresponding author:}

8 Dr Michelle N McDonnell

9 iCAHE

10 University of South Australia

11 GPO Box 2471

12 Adelaide SA 5001

13 Australia

14 Email: michelle.mcdonnell@,unisa.edu.au

15 Phone: +618 83021684

16 Fax: +61883022168 
BACKGROUND

18 Stroke remains the leading cause of serious long-term disability, with direct and indirect costs in the United States in 2009 totalling \$38.6 billion and increasing rapidly ${ }^{1}$. It is well established that a healthy lifestyle reduces the risk of stroke by up to $80 \%$, and undertaking regular physical activity (PA) is an important component of this ${ }^{2}$. Physical inactivity is a powerful risk factor for stroke, with a large multinational case-control study demonstrating that inactivity is the second greatest risk factor for stroke following hypertension ${ }^{3}$. Despite this, interventions to improve uptake of adherence to PA recommendations have received little research attention, with emphasis instead on controlling risk factors such as hypertension, body mass index, cholesterol and diabetes. While this has demonstrated significant impact on stroke reduction ${ }^{4}$, there is still a pressing need to do more to reduce stroke incidence and mortality.

Although the precise amounts and type of exercise required to prevent stroke are unclear, metaanalyses conclude that regular PA reduces the risk of stroke by $25-30 \%$ when compared with the least active people $\mathrm{e}^{5,6}$. In a telephone survey of residents in the US state of Ohio, only $11 \%$ of the 2173 respondents were aware that lack of exercise was a risk factor for stroke ${ }^{7}$, with more recent data from Ireland showing a higher proportion (32.5\%) but still generally a low awareness ${ }^{8}$. Physical inactivity is occasionally even overlooked by researchers considering important modifiable risk factors for stroke when studying awareness of stroke in the community ${ }^{9}$. to 74 , and $53 \%$ of those aged $\geq 75$, being classified as inactive (not undertaking any light/moderate or vigorous activity of at least 10 minutes per day $)^{10}$. Older adults frequently report poor health, lack of company and lack of interest as the main barriers to PA ${ }^{11}$. Increasing our awareness of the barriers and facilitators to exercise in stroke-free individuals at risk of stroke 
40 will enable the targeting of health promotion activities to these groups, particularly those with

41 hypertension, diabetes and previous transient ischaemic attack (TIA).

42 The purpose of this study was to interview people recently admitted to hospital with a first-ever

43 stroke to explore their PA patterns prior to their stroke, whether they were aware of the link

44 between stroke and PA and their understanding of what PA involves. A further aim was to

45 examine barriers and facilitators to PA, to highlight which factors may be modifiable and could

46 be addressed to prevent stroke.

\section{Methods}

\section{Study population}

49 This cross-sectional study recruited adults with first-ever stroke from the acute stroke units of

50 two local metropolitan hospitals and included quantitative and qualitative components.

51 Participants were included if they had a first-ever stroke and were aged 40 to 90 years.

52 Participants were excluded if they had a history of dementia, had receptive and expressive

53 language difficulties which would impact upon their ability to take part in the interview, and were

54 drowsy or otherwise unable to cooperate. All participants gave their informed written consent for

55 the study which was approved by the relevant Research Ethics Committees (the University of

56 South Australia, Royal Adelaide Hospital and Southern Adelaide Clinical Human Research Ethics

57 Committee).

\section{Protocol}

59 Eligibility criteria were verified from medical records. Interviews were conducted on the hospital

60 ward, within a month of their stroke. First, three open ended questions were posed to understand

61 how people with stroke view the relationship between PA and stroke risk, as previously used to 
62 attitudes towards PA in people with hypertension ${ }^{12}$. This method allows participants to share their 63 experiences from their own point of view, and allows for themes to emerge based on participants' 64 perceptions of illness:

65 1. Over the past month, did you do anything to maintain or increase your PA?

66 2. How do you view the link between stroke and PA?

67 3. What would you define as PA?

68 The interviewer prompted with specific examples if required.

69 The second part of the interview involved completing the Barriers to Physical Activity in

Disability Survey (B-PADS) ${ }^{13}$. The B-PADS comprises 34 items, the majority being yes/no

71 questions designed to explore barriers (personal, environmental and/or facility related) that might

72 influence exercise participation (e.g. have you ever been injured from exercising before? Are you

73 concerned that exercise could make your condition worse?). This tool has been validated in

74 people following stroke living in the community and has high reproducibility (Cohen's $\kappa 0.76$ )

75 and inter-rater reliability $(\kappa=0.86)^{\frac{13}{3}}$.

76 The interview times ranged from 8-25 minutes. All interviews were digitally recorded and

77 transcribed verbatim.

78 Data Analysis

79 Data were summarised with appropriate descriptive statistics (mean and standard deviation (SD)

80 for continuous variables, count and frequency for categorical variables). For the primary

81 outcome, PA habits and awareness of PA as a risk factor for stroke, transcripts were examined and

82 analysed using summative content analysis ${ }^{\underline{14}}$ to identify related concepts and determine frequency

83 of these concepts within participants' responses. This method of analysis has the advantage of 
84 being unobtrusive but also allowing interpretation of the underlying meaning of the content

$85\{$ Hsieh, $2005 \# 2415\}$. Two investigators (MMcD and RSW) independently generated initial 86 codes from interview transcripts, before focusing and grouping the codes into concepts. Concepts

87 were refined and named, and transcripts reviewed again to verify against coded data extracts. The

88 frequency of these concepts within the sample of responses was calculated and reported as a

89 percentage of the total number of terms coded for each question. To address the secondary aim,

90 barriers to participating in PA in this population pre-stroke, frequency of responses to the B-

91 PADS were summarised. Associations between variables were explored with generalized linear

92 models using STATA ${ }^{\circledR}$ software (Version 10) and $\mathrm{p}<0.05$ was considered statistically

93 significant.

\section{RESULTS}

95 Demographic data for the 81 adults recruited are provided in Table 1. Two thirds of the

96 participants were male, the mean age was 67 years and they were interviewed approximately one

97 week after their first-ever stroke.

\section{Physical activity prior to stroke}

Participants, who were within a month of their first-ever stroke $(n=81)$, were asked about their PA levels in the month prior to their stroke. There were a variety of responses, often involving more than one category, and $81 \%$ of participants reported that they did some form of PA in the month prior to their stroke. The common responses, and associated categories, are shown in Table 2 .

The majority of participants reported that the only regular PA they did in the month prior to the stroke consisted of instrumental activities of daily living (IADL), as mentioned by Participant \#66: 

124 (Figure 1) and is illustrated by this quote: counted their steps: days I reached that". Participant \#40. very much at all". Participant \#69.

\section{The link between stroke and PA}

No, I don't know l'm not the doctor!" Participant \#7. history as the cause for their stroke.

"Shopping and putting away of groceries. Usually an hour, not every day, two times a week".

Almost half of the participants reported they did some form of walking each day, and some even

“Walking, things like that. I don't get up and go for a ten km walk. I just walk a lot. 9000 steps, and most

Only 25 of the 81 participants reported regular exercise in the month prior to their stroke, with swimming, golf, attending the gym and running given as examples.

Of those 19 participants who did not undertake any regular PA in the month prior to their stroke, many gave examples of falls, pain or other conditions which limited their activity.

"I was a slug. Because I have been having trouble with my back. I haven't been able to do anything

The responses to the question "How do you view the link between stroke and PA" were assigned a dominant response per participant. This revealed a striking lack of awareness of physical inactivity as a strong risk factor for stroke. Two participants suggested that too much PA in the days leading up actually caused their stroke. The majority of respondents (41\%) had never considered the possibility that the two factors were linked and frequently used the term "no idea"

Many participants felt that PA was unrelated to stroke, and gave examples of stress, diet or family 

"I don't think there is a link between stroke and physical activity, I don't know about diet but smoking seems to be a bad one for me!" Participant \#4.

"I think it could, I had it in my family. My mum passed away with a stroke". Participant \#50.

\section{Definition of $P A$}

Finally, in response to the question "What would you define as physical activity?" there was a lot of overlap between categories, as shown in Table 3. Again, PA was defined using examples of IADLs such as gardening, shopping and housework (47 participants) or walking (57 participants).

One in four participants reflected upon what they had done recently, for example:

"In general, everything that I do. I do my back garden, take my walker and do my walking" Participant $\# 13$.

A number of participants required prompting to answer this question, and this often led to mentioning sport as the definition of PA:

"Exercise and going to gym and things like that. Playing sports". Participant \#34.

\section{Barriers to Physical Activity Survey}

The B-PADS survey was used to collect information on the types of barriers that participants may perceive related to exercise participation. The majority of participants had exercised regularly in the past (58 participants, $72 \%$ ) although many reported that they had stopped regular exercise decades ago. Few participants had been advised to exercise by their regular doctor $(n=20,25 \%)$ and of those who were advised to exercise, only half were told to do anything specific. Despite 
147 this, $80 \%$ of participants $(n=65)$ felt that an exercise program could help them, and $77 \%$ of

148 participants $(n=62)$ were aware of a fitness centre that they could get to. However, $31 \%$ of

149 participants $(n=25)$ reported that health problems have caused them to stop exercising, and a

150 similar proportion $(32 \%, \mathrm{n}=26)$ had been injured from exercising in the past.

151 The barriers to PA reported by participants were most frequently intrinsic personal factors, as 152 shown in Table 3.

\section{Relationship between variables}

154 To explore the effect of participant characteristics on the likelihood of being regularly active,

155 participants were grouped into those who did regular exercise (regular walking or other exercise

156 such as golf, of going to the gym, 46\%) and those who did not exercise regularly in the past

157 month (54\%). There was a significant inverse relationship between age and likelihood of being

158 active, with a 30\% increase in physical inactivity with each decade of advanced age $(\mathrm{p}=0.01$,

159 Incidence Rate Ratio 1.30). There was no association between walking aid use (no aid vs walking

$160 \mathrm{stick} /$ frame/wheelchair prior to stroke $)$ and being active $(\mathrm{p}=0.29)$ or between awareness of

161 physical inactivity as a risk factor for stroke and likelihood of being active in the month prior to

162 stroke $(\mathrm{p}=0.43)$.

\section{DISCUSSION}

164 The primary outcome of this study was to understand PA preferences and the association of PA

165 with stroke risk. We found that in the month prior to their stroke, participants were much more

166 likely to be involved in IADL and walking than sports and other formal modes of exercise. The

167 majority of participants had never considered the relationship between PA and stroke, and only 
168

169

170

171

172

one third were aware that inactivity was in fact a risk factor for stroke. Few participants were advised to exercise by their local doctor, despite two-thirds of the participants having hypertension and almost half suffering from at least one cardiac complaint. These results must be interpreted with caution, however, due to the retrospective nature of our study design.

This study highlights the steps that need to be taken to increase the awareness of physical inactivity as a powerful stroke risk factor, and to raise awareness of the impact that healthy lifestyle choices can have on reducing their risk of stroke. One quarter of participants had a fatalistic attitude to their own stroke, reporting that it was inevitable due to family history or because they were unlucky: "I think it's a roll of the dice" Participant \#37.

When asked what physical activity they had done in the month prior to their stroke, $81 \%$ of participants responded that they were physically active. However, when questioned further it was clear that only $30 \%$ were involved in regular moderately intense exercise. In this sample of older adults, many defined PA as walking but their only regular PA were IADLs such as housework and gardening.

The B-PADs survey revealed that environmental barriers were not a concern for the majority of people prior to stroke. Most participants knew of a local fitness centre, and transport was not an issue. This contrasts markedly from the results of Rimmer et al $1^{\frac{13}{3}}$ where community-dwelling stroke survivors reported environmental/facility barriers much more frequently. A notable difference is that our participants were reflecting back to their activity levels prior to stroke. In this context, our findings are similar to the work of Moschny et al ${ }^{11}$ with healthy older adults who report poor health (58\%), lack of company (43\%) and lack of interest (37\%) as the most frequent barriers to PA. 
The overwhelming majority of participants responded that intrinsic personal factors limited their

191 desire to take part in exercise, most commonly lack of interest, motivation and energy. Some participants expressed a strong dislike of exercise, although they considered themselves to be physically active. The challenge in these individuals is to engage them in activities that they are interested in, focusing on the social aspects and the possibility that physical activity can be enjoyable for physical health and mental well-being ${ }^{11}$, and move away from structured regimes involving limited exercise options. This is particularly important given the $30 \%$ decrease in PA for each decade of advanced age: finding physical activities that are safe and interesting for older adults to participate in may help prevent the age-related decline in PA.

Although many participants did suffer from cardiac conditions and other co-morbidities such as asthma, diabetes and arthritis, less than a third of participants reported that health concerns prevented them from exercising. This may in part be due to the poor awareness of the role of physical activity in managing and improve conditions such as diabetes and cardiovascular disease. The challenge for primary prevention is to encourage people to take up regular exercise, particularly if they do present with other stroke risk factors in the hope that early intervention can prevent later stroke and profound disability. Even those who have not participated in exercise recently can be reassured that in the event of a stroke, higher PA levels in the month prior to stroke are associated with better short-term functional outcomes after stroke $\mathrm{e}^{15}$.

A limitation of this study was that we did not quantify the amount or intensity of physical activity that was performed in the month prior to the stroke. This could have been done to ascertain whether participants met the recommended Physical Activity guidelines $\frac{16}{}$, or quantified their PA

211 in terms of metabolic units per week using the International Physical Activity Questionnaire ${ }^{17}$.

212 This is an inherent limitation of the retrospective design of the study, and reports of PA may be 213 influenced by the stroke event itself. This was not completed partly because of the likelihood of 
214 recall bias but also to avoid any distress that may be caused by such questioning so close to their

215 stroke event. Future studies should address this, because of the known link between moderately 216 vigorous physical activity and reduced risk of stroke ${ }^{18}$. However, a strength of this study was the

217 relatively large sample size for a qualitative study, allowing insights into physical activity habits

218 which may not have been captured with standardised surveys.

219 CONCLUSIONS

220 Adults who have recently suffered a stroke report little motivation to undertake exercise, and

221 little awareness of the risk of stroke from low levels of physical activity. They define physical

222 activity using low intensity activities like shopping and walking, and these are the most common

223 forms of PA that they undertake. The challenge for future health care policy is to increase

224 awareness of PA as a modifiable risk factor for stroke, and engage older adults in suitable ways to

225 increase their PA, particularly moderately intense activity in accordance with PA guidelines. 


\section{REFERENCES}

227 1. Go AS, Mozaffarian D, Roger VL, Benjamin EJ, Berry JD, Borden WB, Bravata DM, Dai

228 S, Ford ES, Fox CS, Franco S, Fullerton HJ, Gillespie C, Hailpern SM, Heit JA, Howard VJ, 229 Huffman MD, Kissela BM, Kittner SJ, Lackland DT, Lichtman JH, Lisabeth LD, Magid D, 230 Marcus GM, Marelli A, Matchar DB, McGuire DK, Mohler ER, Moy CS, Mussolino ME, Nichol 231 G, Paynter NP, Schreiner PJ, Sorlie PD, Stein J, Turan TN, Virani SS, Wong ND, Woo D, Turner 232 MB. Heart disease and stroke statistics--2013 update: a report from the American Heart 233 Association. Circulation. 2013;127:e6-e245.

234 2. Chiuve SE, Rexrode KM, Spiegelman D, Logroscino G, Manson JE, Rimm EB. Primary 235 prevention of stroke by healthy lifestyle. Circulation. 2008;118:947-54.

236 3. O'Donnell MJ, Xavier D, Liu L, Zhang H, Chin SL, Rao-Melacini P, Rangarajan S, Islam 237 S, Pais P, McQueen MJ, Mondo C, Damasceno A, Lopez-Jaramillo P, Hankey GJ, Dans AL, 238 Yusoff K, Truelsen T, Diener HC, Sacco RL, Ryglewicz D, Czlonkowska A, Weimar C, Wang X, 239 Yusuf S, investigators I. Risk factors for ischaemic and intracerebral haemorrhagic stroke in 22 240 countries (the INTERSTROKE study): a case-control study. Lancet. 2010;376:112-23.

241 4. Kahn R, Robertson RM, Smith R, Eddy D. The impact of prevention on reducing the 242 burden of cardiovascular disease. Circulation. 2008;118:576-85.

243 5. Goldstein LB, Bushnell CD, Adams RJ, Appel LJ, Braun LT, Chaturvedi S, Creager MA, 244 Culebras A, Eckel RH, Hart RG, Hinchey JA, Howard VJ, Jauch EC, Levine SR, Meschia JF, 
245 Moore WS, Nixon JV, Pearson TA. Guidelines for the primary prevention of stroke: a guideline 246 for healthcare professionals from the American Heart Association/American Stroke Association.

247 Stroke. 2011;42:517-84.

248 6. Lee CD, Folsom AR, Blair SN. Physical activity and stroke risk: a meta-analysis. Stroke. $249 \quad 2003 ; 34: 2475-81$.

250 7. Schneider AT, Pancioli AM, Khoury JC, Rademacher E, Tuchfarber A, Miller R, Woo D, 251 Kissela B, Broderick JP. Trends in community knowledge of the warning signs and risk factors 252 for stroke. JAMA. 2003;289:343-6.

253 8. Hickey A, Holly D, McGee H, Conroy R, Shelley E. Knowledge of stroke risk factors and 254 warning signs in Ireland: development and application of the Stroke Awareness Questionnaire 255 (SAQ). Int J Stroke. 2012;7:298-306.

256 9. Kleindorfer D, Khoury J, Broderick JP, Rademacher E, Woo D, Flaherty ML, Alwell K, 257 Moomaw CJ, Schneider A, Pancioli A, Miller R, Kissela BM. Temporal trends in public 258 awareness of stroke: warning signs, risk factors, and treatment. Stroke. 2009;40:2502-6.

259 10. Schiller JS, Lucas JW, Ward BW, Peregoy JA. Summary health statistics for U.S. adults: 260 National Health Interview Survey, 2010. Vital Health Stat 10. 2012;1-207.

261 11. Moschny A, Platen P, Klaassen-Mielke R, Trampisch U, Hinrichs T. Barriers to physical 262 activity in older adults in Germany: a cross-sectional study. Int J Behav Nutr Phys Act. $2632011 ; 8: 121$. 
264 12. Beune EJ, Haafkens JA, Agyemang C, Bindels PJ. Inhibitors and enablers of physical 265 activity in multiethnic hypertensive patients: qualitative study. J Hum Hypertens. 2010;24:28026690.

267 13. Rimmer JH, Wang E, Smith D. Barriers associated with exercise and community access 268 for individuals with stroke. J Rehabil Res Dev. 2008;45:315-22.

269 14. Kondracki NL, Wellman NS, Amundson DR. Content analysis: review of methods and 270 their applications in nutrition education. Journal of nutrition education and behavior. $271 \quad 2002 ; 34: 224-30$.

272 15. Stroud N, Mazwi TM, Case LD, Brown RD, Jr., Brott TG, Worrall BB, Meschia JF. 273 Prestroke physical activity and early functional status after stroke. J Neurol Neurosurg 274 Psychiatry. 2009;80:1019-22.

275 16. Department of Health and Aged Care. National Physical Activity Guidelines for 276 Australians. Department of Health and Aged Care, editor. Canberra: DHAC; 1999.

277 17. Hagstromer M, Oja P, Sjostrom M. The International Physical Activity Questionnaire 278 (IPAQ): a study of concurrent and construct validity. Public Health Nutr. 2006;9:755-62.

279 18. McDonnell MN, Hillier SL, Hooker SP, Le A, Judd SE, Howard VJ. Physical Activity 280 Frequency and Risk of Incident Stroke in a National US Study of Blacks and Whites. Stroke. $281 \quad 2013 ; 44: 2519-24$. 


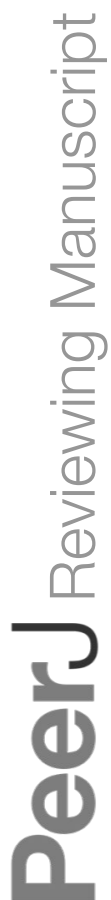

PeerJ reviewing PDF | (v2014:04:2006:1:1:NEW 9 Jun 2014) 
282

283

284

285

Figure 1 title: Responses to the question "How do you view the link between stroke and PA".

Figure 1: Proportion of responses to the question "How do you view the link between stroke and PA" coded as: PA can cause a stroke $(3 \%)$, they are unrelated $(25 \%)$, PA reduces stroke risk (31\%) or no awareness stroke of a link (no idea) $(41 \%)$ 
286 Table 1. Demographic characteristics of participants

287 Table 2. Physical activity levels in the month prior to stroke.

288 Table 3. Definition of PA

289 Table 4. Self-reported barriers to physical activity prior to a first-ever stroke, according to 290 the Barriers to Physical Activity and Disability Survey 


\section{Table 1 (on next page)}

Demographic characteristics of participants 
Table 1. Demographic characteristics of participants

$$
\mathrm{n}=81
$$

Sex

Age (mean, SD)

Days since stroke (median, range)

Stroke type, infarct (n, \%)

Stroke location, cortical stroke (n, \%)

Stroke risk factors $(\mathrm{n}, \%)$

Hypertension

Diabetes

Current smoker

Hypercholesterolaemia

Previous TIA

Cardiac complications*, $\geq 1$

Number of other comorbidities $\dagger$ (median,
$54 \mathrm{M}, 27 \mathrm{~F}$

$67.6 \pm 13.2$

$6(1-30)$

$56(69 \%)$

$44(54 \%)$

$53(65 \%)$

$16(20 \%)$

$21(26 \%)$

$28(35 \%)$

$7(9 \%)$

$34(42 \%)$

$3.8(1-10)$

range)

*Cardiac complications included, but were not limited to, ischaemic heart disease, myocardial infarct, coronary artery bypass grafts, heart failure, permanent pacemaker, atrial fibrillation, cardiomyopathy, congestive cardiac failure

†Other comorbidities included, but were not limited to, depression, emphysema, rheumatoid arthritis, joint replacements, hypothyroidism, obesity, diabetes, renal failure, anaemia, chronic obstructive pulmonary disease. 


\section{Table 2 (on next page)}

Physical activity levels in the month prior to stroke. 
Table 2. Physical activity levels in the month prior to stroke.

\begin{tabular}{ll}
\hline Question: Over the past month, did you do anything to maintain or & Number of codes identified \\
$\begin{array}{ll}\text { increase your physical activity? } & \text { and \% of responses } \\
& \text { compared to total number } \\
\text { of responses }\end{array}$ \\
\hline
\end{tabular}

\begin{tabular}{llr}
\hline Yes (81\% & Walking & $43,30 \%$ \\
participants) & & \\
& IADLs e.g. shopping, work & $54,38 \%$ \\
& Regular exercise e.g. gym, running, swimming & $25,18 \%$
\end{tabular}

No (19\% Unable to (too hot, recently unwell) or don't need/want to $\quad 19,14 \%$

participants) 


\section{Table 3 (on next page)}

\section{Definition of PA}




\section{Table 3. Definition of PA}

Question: "What would you define as physical activity?"

1. Walking for exercise

2. IADL related

3. When prompted for examples then sport mostly

4. Egocentric, what they had done in past months to years

5. Physiological definition
Number of codes identified and \% of

responses compared to total number of responses

$57,26 \%$

$47,22 \%$

$51,23 \%$

$26,12 \%$

$37,17 \%$ 


\section{Table 4 (on next page)}

Self-reported barriers to physical activity prior to a first-ever stroke, according to the Barriers to Physical Activity and Disability Survey 
1 Table 4. Self-reported barriers to physical activity prior to a first-ever stroke, according

2 to the Barriers to Physical Activity and Disability Survey

\begin{tabular}{ll}
\hline Barrier & \% of participants \\
& $(\mathbf{n}=\mathbf{8 1})$ \\
\hline Personal & 58 \\
Lack of motivation & 50 \\
Lack of interest & 42 \\
Lack of energy & 42 \\
Exercise is boring or monotonous & 40 \\
Lack of time & 31 \\
Pain prevents me from exercising & 29 \\
Health concerns prevent me from exercising & \\
& \\
\hline Environmental/Facility & 23 \\
Cost of the program & 36 \\
Lack of transportation & 26 \\
Not aware of fitness centre in the area & \\
Don't feel trainer in facility is able to help & \\
\hline
\end{tabular}

3

4 


\section{Figure 1}

Responses to the question "How do you view the link between stroke and PA".

Proportion of responses to the question "How do you view the link between stroke and PA" coded as: PA can cause a stroke (3\%), they are unrelated (25\%), PA reduces stroke risk (31\%) or no awareness stroke of a link (no idea) $(41 \%)$.

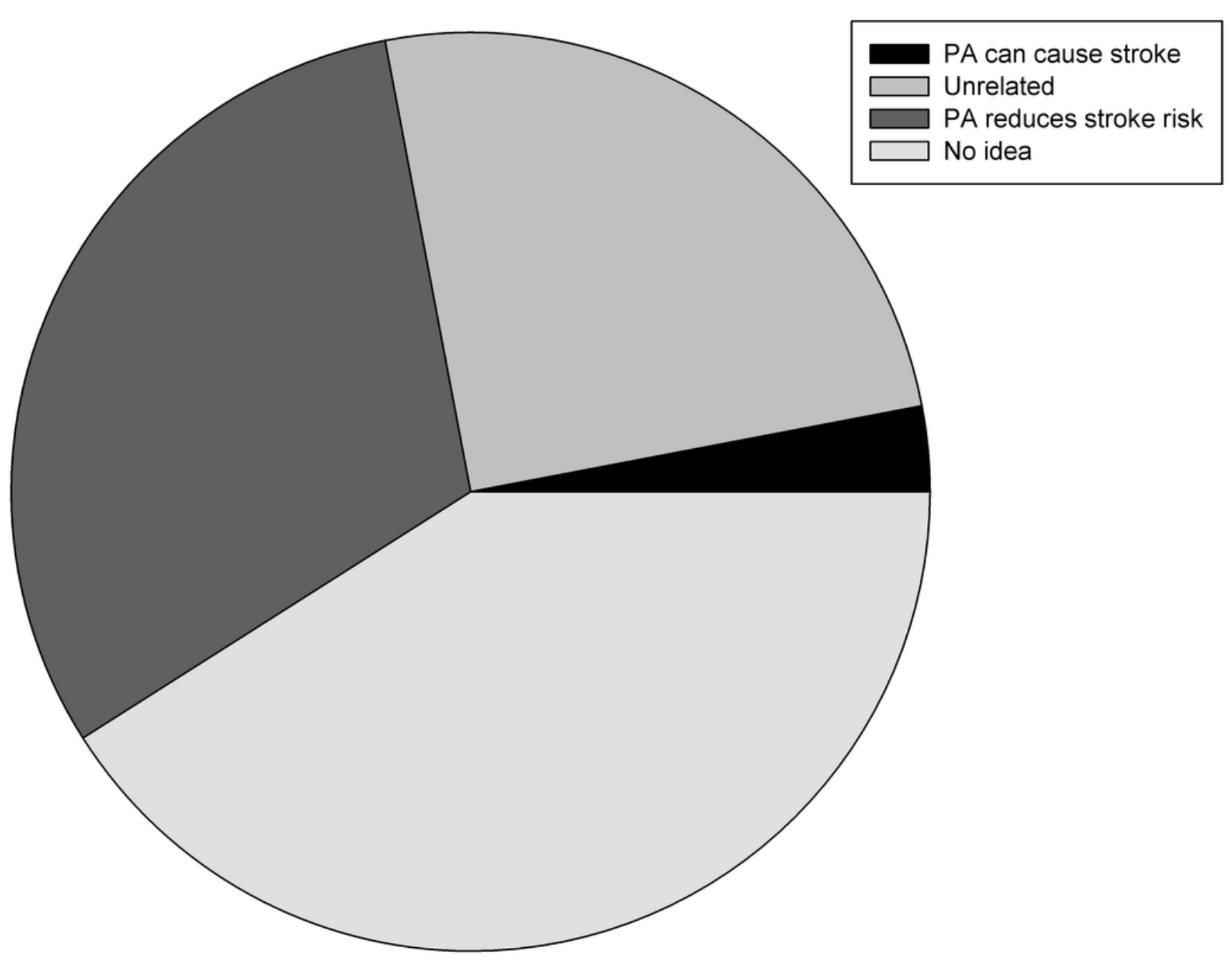

